\title{
Molecular characteristics and virulence gene profiles of Staphylococcus aureus isolates in Hainan, China
}

\author{
Xuehan $\mathrm{Li}^{1 \dagger}$, Tao Huang ${ }^{2+}$, Kai $\mathrm{Xu}^{2}$, Chenglin $\mathrm{Li}^{3}$ and Yirong $\mathrm{Li}^{1^{*}}$
}

\begin{abstract}
Background: There have been no reports regarding the molecular characteristics, virulence features, and antibiotic resistance profiles of Staphylococcus aureus (S. aureus) from Hainan, the southernmost province of China.

Methods: Two hundred twenty-seven S. aureus isolates, consisting of 76 methicillin-resistant S. aureus (MRSA) and 151 methicillin-susceptible S. aureus (MSSA), were collected in 2013-2014 and 2018-2019 in Hainan, and investigated for their molecular characteristics, virulence genes, antibiotic resistance profiles and main antibiotic resistance genes.

Results: Forty sequence types (STs) including three new STs (ST5489, ST5492 and ST5493), and 79 Staphylococcal protein A (spa) types were identified based on multilocus sequence typing (MLST) and spa typing, respectively. ST398 $(14.1 \%, 32 / 227)$ was found to be the most prevalent, and the prevalence of ST398-MSSA increased significantly from 2013 to 2014 (5.5\%, 5/91) to 2018-2019 (18.4\%, 25/136). Seventy-six MRSA isolates were subject to staphylococcus chromosomal cassette mec (SCCmec) typing. SCCmec-IVa was the predominant SCCmec type, and specifically, ST45-SCCmec IVa, an infrequent type in mainland China, was predominant in S. aureus from Hainan. The antibiotic resistance profiles and antibiotic resistance genes of $S$. aureus show distinctive features in Hainan. The resistant rates of the MRSA isolates to a variety of antibiotics were significantly higher than those of the MSSA isolates. The predominant erythromycin and tetracycline resistance genes were ermC $(90.1 \%, 100 / 111)$ and tetK (91.8\%, 78/85), respectively. Eleven virulence genes, including the Panton-Valentine leukocidin (pv) and eta, were determined, and the frequency of eta and pvl were found to be 57.3 and $47.6 \%$. Such high prevalence has never been seen in mainland China before.
\end{abstract}

Conclusion: S. aureus isolates in Hainan have unique molecular characteristics, virulence gene and antibiotic resistance profiles, and main antibiotic resistance genes which may be associated with the special geographical location of Hainan and local trends in antibiotic use.

Keywords: Staphylococcus aureus, Virulence gene, Molecular characterization, Antimicrobial susceptibility test

\section{Background}

Staphylococcus aureus (S. aureus) is an important Grampositive pathogen that causes various infectious diseases including pneumoniae and bacteremia. A previous study showed that patients with $S$. aureus infections had an excess one-year mortality of $20.2 \%$ compared with matched uninfected inpatients [1]. The genotype of $S$.

\footnotetext{
* Correspondence: liyirong838@163.com

†Xuehan Li and Tao Huang contributed equally to this work.

'Department of Laboratory Medicine, Zhongnan Hospital, Wuhan University,

169 Donghu Road, Wuhan 430071, People's Republic of China

Full list of author information is available at the end of the article
}

aureus has been reported to influence the complications, severity, and mortality of infection. One study showed that the strains clonal complex 5 (CC5) and CC30 exhibited a significant trend toward increasing levels of hematogenous complications [2]. Another study found that patients with $S$. aureus sequence type 121 (ST121) infections often required longer hospitalization and prolonged antimicrobial therapy [3], whereas bloodstream infections by CC398, a methicillin-susceptible Staphylococcus aureus (MSSA), were associated with high mortality [4]. Therefore, analysis of the molecular

(C) The Author(s). 2019 Open Access This article is distributed under the terms of the Creative Commons Attribution 4.0 International License (http://creativecommons.org/licenses/by/4.0/), which permits unrestricted use, distribution, and 
characteristics and virulence gene profiles of $S$. aureus is important for prognosis of infection.

The molecular characteristics of $S$. aureus vary with region. In many Asian countries including China and Thailand, ST239 has been found to be the most prevalent type [5-8], whereas in the United States, ST8 (USA300) and ST121 are the most frequently observed $[3,9]$. Even within China, the molecular characteristics of $S$. aureus isolates differ among cities; the predominant types in Wenzhou are ST188 and ST7 [10], the major type in Dalian and Shenyang is ST5 [11], and in Chengdu, ST59 is prevalent [12]. The molecular characteristics of $S$. aureus are also reported vary over time. Since 2000, ST239-t030-SCCmecIII has rapidly replaced ST239-t037-SCCmecIII as the major clone of S. aureus isolates in Chinese tertiary hospital care [2], whereas ST239-t030-MRSA, which in 2013 was the predominant genotype among all methicillin-resistant $S$. aureus (MRSA) strains in China, had been replaced by ST59t437-MRSA by 2016 [13]. In addition, it was reported that the predominant clones, ST239-t030 and ST239t037, were being replaced by the continually growing ST5-t2460 clone in 2017 in Shanghai [14]. Therefore, when monitoring the molecular characteristics of $S$. aureus isolates, it is preferable to focus on a specific region of interest at a particular time.

Hainan, the southernmost province of China, is surrounded by the South China Sea, and has a uniquely tropical monsoon and marine climate that differs significantly from that on the mainland. The island has been called a "natural large greenhouse," and the hot and humid climate is conducive to bacterial growth. Studies of the molecular characteristics and antibiotic resistance profiles of $S$. aureus isolates from China have been carried out over the last 10 years in provinces such as Zhejiang, Guangdong, and Guangxi [15-18]. To date, however, no study has focused on the molecular characteristics and virulence gene profiles of $S$. aureus isolates in Hainan, and no hospital in Hainan has been included in any multicenter studies concerned with those characteristics of $S$. aureus in China [13, 19, 20]. Not even the CHINET surveillance system includes any hospital from Hainan. Although the total area of Hainan is relatively small, its population has now reached 10 million, and moreover, its tropical monsoon and marine climate is unique in China. These are important motivations to investigate the molecular characteristics, virulence genes, and antibiotic resistance profiles of $S$. aureus isolates from Hainan.

\section{Methods}

S. aureus isolates and primers

A total of 227 consecutive and non-duplicate S. aureus isolates were collected from three hospitals in 2013- $2014(n=91)$ and 2018-2019 $(n=136)$. Of the three hospitals in Haikou city, Hainan General Hospital is a large teaching hospital with more than 100,000 admissions per year in Xiuying district; Haikou People's Hospital is a medium-sized teaching hospital with about 50 , 000 admissions per year in Meinan district; and First Hospital Affiliated to Hainan Medical College is a medium-sized teaching hospital with 50,000 admissions per year in Longhua district. These isolates were collected from inpatients who had cough, fever and other clinical symptoms related to infection and whose peripheral white blood cell and/or neutrophil counts were elevated. These isolates were derived from diverse clinical specimens, including cutaneous abscess and wound secretion $(n=110,48.5 \%)$, sputum and pharynx swabs ( $n=48,21.1 \%)$, blood $(n=42,18.5 \%)$, and others (catheter tip, marrow, pleural fluid, cerebrospinal fluid, cystic cavity fluid, drainage liquid, ascites, joint fluid, biopsy, and urine) ( $n=27,11.9 \%)$. Only the first positive culture in the course of infection was included for further analysis. These isolates were identified by conventional microbiological methods including Gram staining, catalase, and coagulase tests, and confirmed with a VITEK 2 Compact system and a VITEK 2 AST-GP67 Test Kit (bioMerieux, Inc., Durham, NC, USA). All isolates were stored at $-80^{\circ} \mathrm{C}$ for further experiments. All primers used in this study were synthesized by Tianyihuiyuan (China) (Table 1). This study was approved by the Ethics Committee of Hainan General Hospital. This was a retrospective study that did not involve collection of clinical and personal information from patients, so informed consent was not required.

\section{Antimicrobial susceptibility testing}

Antimicrobial susceptibility tests were carried out using a VITEK 2 Compact system and a VITEK 2 AST-GP67 Test Kit (bioMerieux, Inc., Durham, NC, USA). Twelve antibiotics were tested, including cefoxitin (FOX), clindamycin (CLI), erythromycin (ERY), gentamicin (GEN), levofloxacin (LEV), linezolid (LZD), oxacillin (OXA), penicillin (PEN), rifampicin (RIF), trimethoprim/sulfamethoxazole (SXT), tetracycline (TET), and vancomycin (VAN). S. aureus ATCC 25923 and ATCC25913 were used as the quality control strains, and the results were interpreted in accordance with Clinical and Laboratory Standards Institute (CLSI) guidelines (CLSI M100-S29) [21]. In addition, $S$. aureus isolates were further identified using PCR for amplification of mecA as described previously [22], in which MRSA N315 was used as the positive control strain. The mecA-positive and cefoxitinresistant isolates (cefoxitin minimum inhibitory concentration $\geq 8 \mu \mathrm{g} / \mathrm{mL}$ ) were identified as MRSA. Isolates resistant to three or more different antimicrobial classes were defined as multidrug-resistant (MDR). 
Table 1 Primers used in this study, and the results of SCCmec types I-V

\begin{tabular}{|c|c|c|c|c|c|c|c|c|c|c|c|c|}
\hline \multirow[t]{2}{*}{ Primer } & \multirow[t]{2}{*}{ Nucleotide sequence $\left(5^{\prime}-3^{\prime}\right)$} & \multirow{2}{*}{$\begin{array}{l}\text { Target } \\
\text { gene }\end{array}$} & \multirow{2}{*}{$\begin{array}{l}\text { Amplicon } \\
\text { size }(b p)\end{array}$} & \multicolumn{9}{|c|}{ scCmec type } \\
\hline & & & & 1 & $\|$ & III & IV & $\mathrm{IVa}$ & $\mathrm{IVb}$ & IVC & $\mathrm{IVd}$ & V \\
\hline$\beta$ & ATTGCCTTGATAATAGCCYTCT & $C C r A 2-B$ & 937 & & $x$ & & $x$ & & & & & \\
\hline a3 & TAAAGGCATCAATGCACAAACACT & & & & & & & & & & & \\
\hline cCrCF & CGTCTATTACAAGATGTTAAGGATAAT & $\operatorname{ccrC}$ & 518 & & & $x$ & & & & & & $x$ \\
\hline cCrCR & CCTITATAGACTGGATTATTCAAAATAT & & & & & & & & & & & \\
\hline $1272 \mathrm{~F} 1$ & GCCACTCATAACATATGGAA & 151272 & 415 & $x$ & & & $x$ & & & & & \\
\hline 1272R1 & CATCCGAGTGAAACCCAAA & & & & & & & & & & & \\
\hline 5RmecA & TATACCAAACCCGACAACTAC & mecA-IS431 & 359 & & & & & & & & & $x$ \\
\hline $5 R 431$ & CGGCTACAGTGATAACATCC & & & & & & & & & & & \\
\hline Type IVa-F & GCCTTATTCGAAGAAACCG & - & 776 & & & & & $x$ & & & & \\
\hline Type IVa-R & CTACTCTTCTGAAAAGCGTCG & & & & & & & & & & & \\
\hline Type IVb-F & TCTGGAATTACTTCAGCTGC & - & 493 & & & & & & $x$ & & & \\
\hline Type IVb-R & AAACAATATTGCTCTCCCTC & & & & & & & & & & & \\
\hline Type IVc-F & ACAATATTTGTATTATCGGAGAGC & - & 200 & & & & & & & $x$ & & \\
\hline Type IVc-R & TTGGTATGAGGTATTGCTGG & & & & & & & & & & & \\
\hline Type IVd-F & CTCAAAATACGGACCCCAATACA & - & 881 & & & & & & & & $x$ & \\
\hline Type IVd-R & TGCTCCAGTAATTGCTAAAG & & & & & & & & & & & \\
\hline Spa-1113f & TAAAGACGATCCTTCGGTGAGC & spa & - & & & & & & & & & \\
\hline Spa-1514r & CAGCAGTAGTGCCGTTGCTT & & & & & & & & & & & \\
\hline $\operatorname{arcC}-\mathrm{F}$ & TTGATTCACCAGCGCGTATTGTC & $\operatorname{arcc}$ & 456 & & & & & & & & & \\
\hline $\operatorname{arcC}-\mathrm{R}$ & AGG TATCTGCTTCAATCAGCG & & & & & & & & & & & \\
\hline aroE-F & ATCGGAAATCCTATTTCACATTC & $\operatorname{aroE}$ & 456 & & & & & & & & & \\
\hline aroE-R & GGTGTTGTATTAATAACGATATC & & & & & & & & & & & \\
\hline glpF-F & CTAGGAACTGCAATCTTAATCC & $g / p F$ & 465 & & & & & & & & & \\
\hline glpF-R & TGGTAAAATCGCATGTCCAATTC & & & & & & & & & & & \\
\hline gmk-F & ATCGTITATCGGGACCATC & gmk & 417 & & & & & & & & & \\
\hline gmk-R & TCATTAACTACAACGTAATCGTA & & & & & & & & & & & \\
\hline pta-F & GTTAAAATCGTATTACCTGAAGG & pta & 474 & & & & & & & & & \\
\hline pta-R & GACCCTITTGTTGAAAAGCTTAA & & & & & & & & & & & \\
\hline tpi-F & TCGTTCATTCTGAACGTCGTGAA & tpi & 402 & & & & & & & & & \\
\hline tpi-R & TTGCACCTTCTAACAATTGTAC & & & & & & & & & & & \\
\hline yqiL-F & CAGCATACAGGACACCTATTGGC & yqil & 516 & & & & & & & & & \\
\hline yqiL-R & CGTTGAGGAATCGATACTGGAAC & & & & & & & & & & & \\
\hline PVL-F & ATCATTAGGTAAAATGTCTGGACATGATCCA & $p v l$ & 433 & & & & & & & & & \\
\hline$P V L-R$ & GCATCAASTGTATTGGATAGCAAAAGC & & & & & & & & & & & \\
\hline FnbA-F & GTGAAGTITAGAAGGTGGAAAGATTAG & $f \cap b A$ & 643 & & & & & & & & & \\
\hline FnbA-R & GCTCTTGTAAGACCATTTTTCTTCAC & & & & & & & & & & & \\
\hline FnbB-F & GTAACAGCTAATGGTCGAATTGATACT & $f n b B$ & 524 & & & & & & & & & \\
\hline FnbB-R & CAAGTTCGATAGGAGTACTATGTTC & & & & & & & & & & & \\
\hline $\mathrm{Hla}-\mathrm{F}$ & CTGATTACTATCCAAGAAATTCGATTG & hla & 209 & & & & & & & & & \\
\hline Hla-R & CTTTCCAGCCTACTTTTTIATCAGT & & & & & & & & & & & \\
\hline Hlb-F & GTGCACTTACTGACAATAGTGC & $h / b$ & 309 & & & & & & & & & \\
\hline Hlb-R & GTTGATGAGTAGCTACCTTCAGT & & & & & & & & & & & \\
\hline Sea-F & GAAAAAAGTCTGAATTGCAGGGAACA & sea & 560 & & & & & & & & & \\
\hline
\end{tabular}


Table 1 Primers used in this study, and the results of SCCmec types I-V (Continued)

\begin{tabular}{|c|c|c|c|c|c|c|c|c|c|c|c|c|}
\hline \multirow[t]{2}{*}{ Primer } & \multirow[t]{2}{*}{ Nucleotide sequence( $\left.5^{\prime}-3^{\prime}\right)$} & \multirow{2}{*}{$\begin{array}{l}\text { Target } \\
\text { gene }\end{array}$} & \multirow{2}{*}{$\begin{array}{l}\text { Amplicon } \\
\text { size }(b p)\end{array}$} & \multicolumn{9}{|c|}{ SCCmec type } \\
\hline & & & & I & II & III & IV & IVa & $\mathrm{IVb}$ & IVc & IVd & $\mathrm{V}$ \\
\hline Sea-R & CAAATAAATCGTAATTAACCGAAGGTTC & & & & & & & & & & & \\
\hline Seb-F & ATTCTATTAAGGACACTAAGTTAGGGA & seb & 404 & & & & & & & & & \\
\hline Seb-R & ATCCCGTTTCATAAGGCGAGT & & & & & & & & & & & \\
\hline Sec-F & GTAAAGTTACAGGTGGCAAAACTTG & $\sec$ & 297 & & & & & & & & & \\
\hline Sec-R & CATATCATACCAAAAAGTATTGCCGT & & & & & & & & & & & \\
\hline eta-F & CGCTGCGGACATTCCTACATGG & eta & 676 & & & & & & & & & \\
\hline eta-R & TACATGCCCGCCACTTGCTTGT & & & & & & & & & & & \\
\hline etb-F & CAGATAAAGAGCTITATACACACATTAC & etb & 612 & & & & & & & & & \\
\hline etb-R & AGTGAACTTATCTITCTATTGAAAAACACTC & & & & & & & & & & & \\
\hline CIfA-F & ATTGGCGTGGCTTCAGTGCT & clfa & 292 & & & & & & & & & \\
\hline ClfA-R & CGTTCTTCCGTAGTTGCATTTG & & & & & & & & & & & \\
\hline ermA-F & GTTCAAGAAC AATCAATACA GAG & ermA & 421 & & & & & & & & & \\
\hline ermA-R & GGATCAGGAA AAGGACATTT TAC & & & & & & & & & & & \\
\hline ermB-F & CCGTTACGA AATTGGAACA GGTAAAGGGC & ermB & 359 & & & & & & & & & \\
\hline ermB-R & GAATCGAGAC TTGAGTGTGC & & & & & & & & & & & \\
\hline ermC-F & GCTAATATTG TITAAATCGT CAATTCC & ermC & 572 & & & & & & & & & \\
\hline ermC-R & GGATCAGGAA AAGGACATTT TAC & & & & & & & & & & & \\
\hline tetM-F & AGTGGAGCGATTACAGAA & tetM & 158 & & & & & & & & & \\
\hline tetM-R & CATATGTCCTGGCGTGTCTA & & & & & & & & & & & \\
\hline tetK-F & GTAGCGACAATAGGTAATAGT & tetk & 360 & & & & & & & & & \\
\hline tetK-R & GTAGTGACAATAAACCTCCTA & & & & & & & & & & & \\
\hline tetL-F & ATAAATTGTTTCGGGTCGGTAAT & tetl & 1077 & & & & & & & & & \\
\hline tetL-R & AACCAGCCAACTAATGACAATGAT & & & & & & & & & & & \\
\hline tetO-F & AACTTAGGCATTCTGGCTCAC & tetO & 514 & & & & & & & & & \\
\hline tetO-R & TCCCACTGTTCCATATCGTCA & & & & & & & & & & & \\
\hline
\end{tabular}

\section{Staphylococcal protein a (spa) typing}

Chromosomal DNAs were extracted from $S$. aureus isolates as described previously [23]. The extracted chromosomal DNAs were stored at $-20^{\circ} \mathrm{C}$ for spa, Staphylococcus chromosomal cassette mec (SCCmec), multilocus sequence typing, and detection of virulence genes. For spa typing, the variable repeat region of spa was amplified using oligonucleotide primers [23, 24] (see Table 1) followed by sequencing. The PCR mixture and conditions were similar to those described previously [23]. The resulting amplicons were purified and subjected to Sanger dideoxy DNA sequencing (Tianyihuiyuan, China) followed by analysis using the Ridom web server (http://spaserver.ridom.de). S. aureus isolates that could not be classified as any known spa type were defined as nontypable (NT).

\section{Multilocus sequence typing (MLST)}

MLST was carried out according to the protocol described previously $[23,25]$. Seven housekeeping genes of
S. aureus-arcC, aroE, glpF, gmk, pta, tpi, and yqil-were adopted for MLST. Seven respective PCR assays were conducted to amplify these seven housekeeping genes. These amplicons were sequenced using Sanger dideoxy DNA sequencing (Tianyihuiyuan, China). The resulting sequences were compared with the known alleles in the MLST database (http://saureus.mlst.net), which was used to determine ST. S. aureus isolates that could not be assigned to any known ST were submitted to the MLST database and assigned to new STs. The clustering of related STs, which were defined as clonal complexes (CCs), was determined using eBURST .

\section{Staphylococcus chromosomal cassette mec (SCCmec) typing}

The MRSA isolates were subjected to SCCmec typing as previously described [26]. MRSA isolates with suspected SCCmecIV were recharacterized by additional multiplex PCR as subtypes IVa, IVb, IVc, and IVd as described by Zhang et al. [22]. MRSA isolates that could not be 
assigned to any above type were defined as NT. All primers are listed in Table 1.

\section{Detection of virulence genes and antibiotic resistance genes}

Eleven virulence genes, including the Panton-Valentine leukocidin $(p v l)$, the staphylococcal enterotoxin genes (sea, seb, sec), the exfoliative toxin genes (eta, etb), the hemolysin genes ( $h l a, h l b)$, and the adhesion factor genes $(f n b A, f n b B, c l f A)$ were detected using PCR assays. The PCR mixture and conditions were similar to those described previously [23]. The common ERY resistance genes (ermA, ermB, ermC), and the TET resistance genes (tet $L$, tet $K$, tet $M$, tet $O$ ) were examined using PCR assays as previously described $[27,28]$.

\section{Statistical analysis}

Statistical analyses were performed using SPSS Statistics 24.0 for Windows. Data were analyzed using the chisquare or Fisher's exact tests. All statistical tests were two-tailed, and $p<0.05$ or $p<0.01$ (Fisher's exact tests among three groups) was considered to indicate statistical significance.

\section{Results}

\section{Antimicrobial susceptibility and antibiotic resistance} genes

A total of 227 S.aureus isolates were tested for antimicrobial susceptibility. The antimicrobial resistance profiles of the $S$. aureus, MRSA, MSSA and MDR isolates are shown in Fig. 1. No S. aureus isolate was resistant to VAN or LZD, but most were resistant to GEN (14.1\%), LEV (10.6\%), and RIF (19.8\%). Less than $50 \%$ of isolates were resistant to the remaining antibiotics, except for PEN, to which $92.5 \%$ had resistance. All of 76 FOX-resistant isolates, including an OXA susceptibleMRSA (OS-MRSA), were found to be mecA-positive, and were thus classified as MRSA isolates. Statistical analysis showed that the MRSA isolates had significantly higher resistance rates to PEN than the MSSA isolates (100.0\% vs. $88.7 \%, p=0.002)$, ERY $(75.0 \%$ vs. $35.8 \%, p<$ $0.001)$, CLI (64.5\% vs. $29.8 \%, p<0.001)$, GEN (18.4\% vs. $8.6 \%, p=0.031)$, RIF ( $17.1 \%$ vs. $4.6 \%, p=0.002)$, and LEV (15.8\% vs. $6.6 \%, p=0.028)$.

A total of 111 ERY-resistant S. aureus isolates were found and used to examine the presence of erm gene. The most prevalent erm gene was ermC (90.1\%, 100/ 111), followed by ermB (38.7\%, 43/111) and ermA $(21.6 \%, 24 / 111)$. In the ERY-resistant MSSA isolates, the frequencies of the three ERY-resistant genes showed the same trend as in the ERY-resistant MRSAs. ermC $(87.0 \%, 47 / 54)$ was the most prevalent gene, followed by $\operatorname{ermB}(38.9 \%, 21 / 54)$ and ermA $(11.1 \%, 6 / 54)$. The ERYresistant MRSA isolates had higher frequencies of ermA than the ERY-resistant MSSA isolates $(x 2=6.855, p<$ 0.05). All of 85 TET-resistant isolates carried the TETresistant genes tet. The prevalences of tetK, tetM, tet $L$ and $t e t O$ were $91.8 \%$ (78/85), 67.1\% (57/85), 23.5\% (20/ $85)$ and $0.0 \%(0 / 85)$, respectively. In the TET-resistant MSSA isolates, the most prevalent TET-resistant gene was still tetK $(93.2 \%, 55 / 59)$, followed by tetM $(59.3 \%$, $35 / 59)$, tetL $(23.7 \%, 14 / 59)$, and tetO $(0.0 \%, 0 / 59)$. TETresistant MRSA isolates had higher frequencies tet $M$ than the TET-resistant MSSA isolates $(\mathrm{X} 2=5.227, p<$ 0.05).

One hundred thirteen (49.8\%) S. aureus isolates were found to be MDR, defined as having resistance to more than three classes of antibiotics (Table 2). The chisquare test showed that the prevalence of MDR was significantly higher in the MRSA isolates than in the MSSA isolates (Table 2$)(x 2=26.115, p<0.05)$. In addition, when comparing the $S$. aureus isolates collected in 2013-2014 with those from 2018 to 2019, the resistance rates to all antibiotics except SXT were broadly similar.

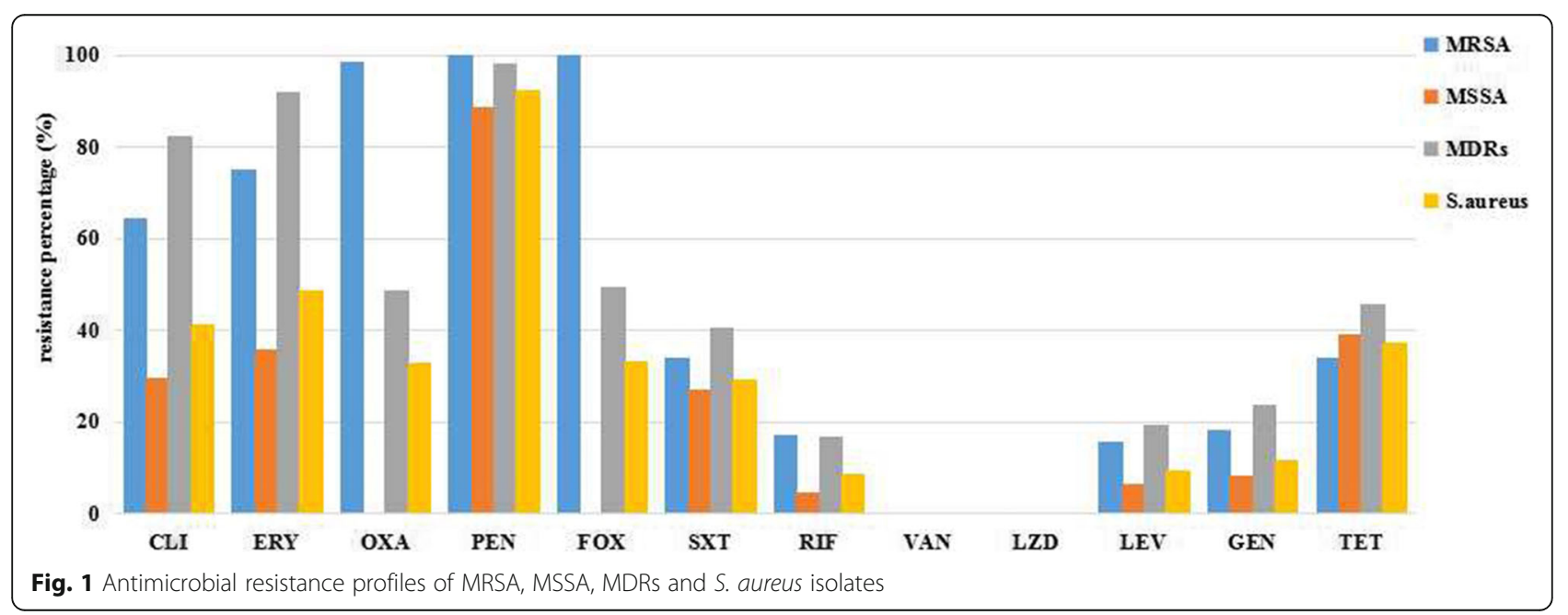


Table 2 The frequency of MDRs, main STs, and virulence genes among MRSA and MSSA

\begin{tabular}{|c|c|c|c|c|c|c|c|c|c|c|c|c|c|c|c|}
\hline \multirow[b]{2}{*}{ isolates(n) } & \multirow{2}{*}{$\begin{array}{l}\text { MDRs } \\
\text { MDRs } \\
(n, \%)\end{array}$} & \multicolumn{3}{|c|}{ Main STs } & \multicolumn{11}{|c|}{ Virulence genes } \\
\hline & & $\begin{array}{l}\text { ST398 } \\
(\mathrm{n}, \%)\end{array}$ & $\begin{array}{l}\text { ST188 } \\
(\mathrm{n}, \%)\end{array}$ & $\begin{array}{l}\text { ST45 } \\
(n, \%)\end{array}$ & $\begin{array}{l}\text { pvl (n, } \\
\%)\end{array}$ & $\begin{array}{l}f n b A \\
(n, \%)\end{array}$ & $\begin{array}{l}f n b B \\
(n, \%)\end{array}$ & $\begin{array}{l}\text { hla (n, } \\
\%)\end{array}$ & $\begin{array}{l}\text { hlb (n, } \\
\%)\end{array}$ & $\begin{array}{l}\text { sea }(n, \\
\%)\end{array}$ & $\begin{array}{l}\text { seb (n, } \\
\%)\end{array}$ & $\begin{array}{l}\sec (n, \\
\%)\end{array}$ & $\begin{array}{l}\text { eta }(\mathrm{n}, \\
\%)\end{array}$ & $\begin{array}{l}\text { etb ( } \mathrm{n}, \\
\%)\end{array}$ & $\begin{array}{l}\text { CIfA (n, } \\
\%)\end{array}$ \\
\hline MRSA(76) & $\begin{array}{l}56 \\
(73.7)\end{array}$ & $2(2.6)$ & $1(1.3)$ & $\begin{array}{l}20 \\
(26.3)\end{array}$ & $\begin{array}{l}31 \\
(40.8)\end{array}$ & $\begin{array}{l}36 \\
(47.4)\end{array}$ & $\begin{array}{l}31 \\
(40.8)\end{array}$ & $\begin{array}{l}74 \\
(97.4)\end{array}$ & $\begin{array}{l}51 \\
(67.1)\end{array}$ & $\begin{array}{l}18 \\
(23.7)\end{array}$ & $\begin{array}{l}38 \\
(50.0)\end{array}$ & $\begin{array}{l}38 \\
(50.0)\end{array}$ & $\begin{array}{l}47 \\
(61.8)\end{array}$ & $\begin{array}{l}15 \\
(19.7)\end{array}$ & $\begin{array}{l}76 \\
(100.0)\end{array}$ \\
\hline MSSA & $\begin{array}{l}57 \\
(37.7)\end{array}$ & $\begin{array}{l}30 \\
(19.9)\end{array}$ & $\begin{array}{l}29 \\
(19.2)\end{array}$ & $3(2.0)$ & $\begin{array}{l}77 \\
(51.0)\end{array}$ & $\begin{array}{l}51 \\
(33.8)\end{array}$ & $\begin{array}{l}82 \\
(54.3)\end{array}$ & $\begin{array}{l}150 \\
(99.3)\end{array}$ & $\begin{array}{l}110 \\
(72.8)\end{array}$ & $\begin{array}{l}17 \\
(11.3)\end{array}$ & $\begin{array}{l}70 \\
(46.4)\end{array}$ & $\begin{array}{l}25 \\
(16.6)\end{array}$ & $\begin{array}{l}83 \\
(55.0)\end{array}$ & $\begin{array}{l}28 \\
(18.5)\end{array}$ & $\begin{array}{l}151 \\
(100.0)\end{array}$ \\
\hline S.aureus(227) & $\begin{array}{l}113 \\
(49.8)\end{array}$ & $\begin{array}{l}32 \\
(14.1)\end{array}$ & $\begin{array}{l}30 \\
(13.2)\end{array}$ & $\begin{array}{l}23 \\
(10.1)\end{array}$ & $\begin{array}{l}108 \\
(47.6)\end{array}$ & $\begin{array}{l}87 \\
(35.7)\end{array}$ & $\begin{array}{l}113 \\
(49.8)\end{array}$ & $\begin{array}{l}224 \\
(98.7)\end{array}$ & $\begin{array}{l}161 \\
(70.9)\end{array}$ & $\begin{array}{l}35 \\
(15.4)\end{array}$ & $\begin{array}{l}108 \\
(47.6)\end{array}$ & $\begin{array}{l}63 \\
(27.8)\end{array}$ & $\begin{array}{l}130 \\
(57.3)\end{array}$ & $\begin{array}{l}43 \\
(18.9)\end{array}$ & $\begin{array}{l}227 \\
(100.0)\end{array}$ \\
\hline$p$ value $^{a}$ & $<0.01$ & $<0.01$ & $<0.01$ & $<0.01$ & 0.146 & 0.047 & 0.055 & 0.542 & 0.369 & 0.014 & 0.604 & $<0.01$ & 0.323 & 0.829 & - \\
\hline
\end{tabular}

${ }^{a}$ The frequency of MDRs, main STs, and virulence genes in MRSA isolates were compared with those in MSSA isolates

Compared with those collected in 2018-2019, the $S$. aureus isolates from 2013 to 2014 had a higher resistance rate to SXT $(64.8 \%$ vs. $5.9 \%, p<0.05)$ and a greater prevalence of MDR $(61.5 \%$ vs. $41.9 \%, p<0.05)$.

\section{MLST, spa, and SCCmec typing}

Forty STs belonging to $19 \mathrm{CCs}$ and 2 singletons were identified by eBURST. As shown in Table 3 and Fig. 2, ST398 $(14.1 \%, 32 / 227)$ was the most prevalent, followed by ST188 $(13.2 \%, 30 / 227)$ and ST45 $(10.1 \%, 23 / 227)$. It was found that $78.1 \%(25 / 32)$ of the ST398 isolates, $80.0 \%(24 / 30)$ of the ST188 isolates, and 91.3\% (21/23) of the ST45 isolates were derived from Hainan General Hospital. In addition, three isolates could not be assigned to any known ST, so these novel alleles were submitted to the MLST database, and three new STs, ST5489, ST5492 and ST5493, were assigned. By spa typing, 79 spa types were found. The most prevalent was t189 $(12.3 \%, 28 / 227)$, followed by $t 437$ (7.9\%, 18/227), t116 $(7.5 \%, 17 / 227)$, and t011 $(6.6 \%, 15 / 227)$. When the STs and spa typing were combined, the predominant combinations were ST188-t189 (12.3\%, 28/227), ST45t116 (7.5\%, 17/227), ST59-t437 (7.0\%, 16/227), ST398t011 (6.6\%, 15/227), ST398-t034 (4.8\%, 11/227), and ST7-t091 (4.8\%, 11/227). A strong association was observed between certain STs and spa types: ST188 was primarily associated with t189 (93.3\%, 28/30); ST45 was associated mainly with t116 (73.9\%, 17/23); and ST59 was associated mainly with $t 437(72.7 \%, 16 / 22)$.

The major types of S. aureus collected in 2013-2014 were ST188 (14.3\%), ST45 (14.3\%), ST59 (8.8\%), and ST88 (8.8\%), whereas in 2018-2019, ST398 (19.9\%), ST188 (12.5\%), ST59 (10.3\%), ST45 (7.4\%), and ST7 (7.4\%) were the top five types. Among the STs that exhibited OXA sensitivity, the two predominant types in 2013-2014 were ST188-MSSA (14.3\%) and ST45-MRSA (12.1\%), whereas in 2018-2019 they were ST398-MSSA (18.4\%) and ST59-MRSA (8.1\%). The prevalence of ST398-MSSA markedly increased from 2013 to 2014 (5.5\%) to $2018-2019(18.4 \%)$, and this increase was significant $(p<0.05)$.
Among the 76 MRSA isolates, 6 SCCmec types or subtypes, namely types I, II, III, IVa, IVc, and V, were found. The most common SCCmec type was IVa, which was found in 43 isolates $(56.6 \%, 43 / 76)$, whereas types I, II, III, IVc, and V were found in 1, 3, 6, 5, and 9 isolates, respectively. Nine isolates, including OS-MRSA, were classified as NT for SCCmec typing. When the STs and SCCmec typing were combined, the predominant combination was ST45-SCCmec IVa (8.8\%, 20/227), and no significant difference was found in the positive rate of ST45-SCCmec IVa between the $S$. aureus isolates collected in 2013-2014 and 2018-2019 (12.1\% vs. 6.6\%, $p>0.05$ ) (Table 3).

\section{Virulence gene profiles}

The frequencies of the virulence genes identified in the 227 S. aureus isolates are listed in Table 4. ClfA was present in all S. aureus isolates, hla, hlb, and eta were detected in $98.7,70.9$, and $57.3 \%$ of these isolates, respectively, whereas the remaining ones were found in less than 50\%. One hundred and twenty (52.9\%) S. aureus isolates harbored six or more virulence genes. Of those 120 isolates, 11 contained 9 virulence genes, 31 had 8 such genes, 38 carried 7, and 40 carried 6 . The frequencies of $f n b A$, sea, and sec were significantly higher in the MRSA isolates than in the MSSA isolates, but no significant difference was found in the likelihood of harboring six or more virulence genes between the MRSA and MSSA isolates $(56.6 \%$ vs. $51.0 \%, p>0.05)$. Compared with those collected in 2013-2014, the S. aureus isolates from 2018 to 2019 had higher frequency of $p v l$, $f n b B, h l b, s e b$, eta, and etb and higher rates of harboring six or more virulence genes.

\section{Characteristics of the major clones ST398, ST188, and ST45}

The most abundant sequence type found in this study was ST398 (14.1\%, 32/227) followed by ST188 (13.2\%, 30/227) and ST45 (10.1\%, 23/227). Most ST398 (93.8\%, $30 / 32)$ and ST188 $(96.7 \%, 29 / 30)$ isolates were MSSA, whereas most ST45 $(87.0 \%, 20 / 23)$ isolates were MRSA 
Table 3 Molecular characteristics of S. aureus isolates collected in this study

\begin{tabular}{|c|c|c|c|c|c|c|c|c|c|c|}
\hline \multirow[t]{2}{*}{ CC (no.) } & \multicolumn{5}{|c|}{ 2013-2014 (91 isolates) } & \multicolumn{5}{|c|}{ 2018-2019 (136 isolates) } \\
\hline & MLST(no.) & spa(no.) & MRSA(no.) & MSSA(no.) & SCCmec(no.) & MLST(no.) & spa(no.) & MRSA(no.) & MSSA(no.) & scCmec(no.) \\
\hline \multirow[t]{6}{*}{ CC398(32) } & ST398(5) & t011(3) & & 3 & & ST398(27) & t011(12) & & 12 & \\
\hline & & $\mathrm{t} 034(2)$ & & 2 & & & t034(9) & 2 & 7 & $V(2)$ \\
\hline & & & & & & & t1451(3) & & 3 & \\
\hline & & & & & & & $\mathrm{t} 571(1)$ & & 1 & \\
\hline & & & & & & & t1580 (1) & & 1 & \\
\hline & & & & & & & NT(1) & & 1 & \\
\hline \multirow[t]{8}{*}{ CC59(30) } & ST59(8) & $\mathrm{t} 437(4)$ & 1 & 3 & $\operatorname{IVa}(1)$ & ST59(14) & $\mathrm{t} 437(12)$ & 9 & & $\mathrm{IVa}(5), \mathrm{V}(4)$ \\
\hline & & $\mathrm{t} 441(1)$ & 1 & & $V(1)$ & & t3385(1) & 1 & & $\operatorname{IVa}(1)$ \\
\hline & & $\mathrm{t} 1212(1)$ & & 1 & & & t5795(1) & 1 & & $\operatorname{IVa}(1)$ \\
\hline & & t2356(1) & 1 & & $\operatorname{IVa}(1)$ & ST338(3) & $\mathrm{t} 437(1)$ & & 1 & \\
\hline & & t3592(1) & 1 & & $V(1)$ & & $\mathrm{t} 1751(2)$ & 2 & & $V(1), N T(1)$ \\
\hline & ST338(2) & $\mathrm{t} 1751(2)$ & & 2 & & & & & & \\
\hline & ST1778(2) & $\mathrm{t} 437(1)$ & & 1 & & ST2041(1) & t13874(1) & & 1 & \\
\hline & & t2365(1) & 1 & & $\operatorname{IVa}(1)$ & & & & & \\
\hline \multirow[t]{2}{*}{ CC188(30) } & ST188(13) & t189(12) & & 12 & & ST188(17) & t189(16) & 1 & 15 & $\operatorname{IVa}(1)$ \\
\hline & & $\mathrm{t} 4950(1)$ & & 1 & & & t2174(1) & & 1 & \\
\hline \multirow[t]{6}{*}{ CC45(25) } & ST45(13) & t116(10) & 8 & 2 & $\operatorname{IVa}(8)$ & ST45(10) & $\mathrm{t} 116(7)$ & 6 & 1 & $\operatorname{IVa}(6)$ \\
\hline & & t015(1) & 1 & & $\operatorname{IVa}(1)$ & & t026(1) & 1 & & $\operatorname{IVa}(1)$ \\
\hline & & $\mathrm{t} 2131(1)$ & 1 & & $\operatorname{IVa}(1)$ & & $\mathrm{t} 157(1)$ & 1 & & $\operatorname{IVa}(1)$ \\
\hline & & NT(1) & 1 & & $\operatorname{IVa}(1)$ & & t3349(1) & 1 & & $\operatorname{IVa}(1)$ \\
\hline & & & & & & ST508(2) & t1203(1) & 1 & & NT(1) \\
\hline & & & & & & & t908(1) & 1 & & $\operatorname{IVa}(1)$ \\
\hline \multirow[t]{9}{*}{ CC5(17) } & ST5(6) & t002(3) & & 3 & & ST5(8) & t2358(2) & 2 & & $\operatorname{IVa}(2)$ \\
\hline & & t954(1) & & 1 & & & t548(1) & & 1 & \\
\hline & & t6212(1) & & 1 & & & $\mathrm{t} 777(1)$ & & 1 & \\
\hline & & t2358(1) & 1 & & $\operatorname{IVa}(1)$ & & t1265(1) & & 1 & \\
\hline & ST965(1) & t062(1) & 1 & & $\operatorname{IVa}(1)$ & & $\mathrm{t} 179(1)$ & & 1 & \\
\hline & & & & & & & t2980(1) & & 1 & \\
\hline & & & & & & & t9987(1) & & 1 & \\
\hline & & & & & & ST764(1) & t1084(1) & 1 & & $\|(1)$ \\
\hline & & & & & & ST2633(1) & t010(1) & & 1 & \\
\hline \multirow[t]{6}{*}{ CC7(17) } & ST7(4) & t091(4) & & 4 & & $\mathrm{ST7}(10)$ & t091(7) & & 7 & \\
\hline & & & & & & & t867(1) & & 1 & \\
\hline & & & & & & & t2874(1) & & 1 & \\
\hline & & & & & & & t3932(1) & & 1 & \\
\hline & ST5489(1) & t091(1) & & 1 & & ST789(1) & t2453(1) & & 1 & \\
\hline & ST4457(1) & t796(1) & & 1 & & & & & & \\
\hline \multirow[t]{5}{*}{ CC88(16) } & ST88(8) & t1376(4) & 1 & 3 & $\|(1)$ & ST88(8) & t1376(3) & 1 & 2 & $\operatorname{IVa}(1)$ \\
\hline & & t2592(1) & 1 & & $\operatorname{IVa}(1)$ & & t4333(2) & & 2 & \\
\hline & & t3622(1) & & 1 & & & NT(3) & & 3 & \\
\hline & & t15796(1) & & 1 & & & & & & \\
\hline & & NT(1) & & 1 & & & & & & \\
\hline $\mathrm{CC} 1(14)$ & ST1(4) & $\mathrm{t} 127(1)$ & & 1 & & ST1(8) & $\mathrm{t} 127(5)$ & 1 & 4 & $\mathrm{NT}(1)$ \\
\hline
\end{tabular}


Table 3 Molecular characteristics of S. aureus isolates collected in this study (Continued)

\begin{tabular}{|c|c|c|c|c|c|c|c|c|c|c|}
\hline \multirow[t]{2}{*}{$\overline{C C}($ no.) } & \multicolumn{5}{|c|}{ 2013-2014 (91 isolates) } & \multicolumn{5}{|c|}{ 2018-2019 (136 isolates) } \\
\hline & MLST(no.) & spa(no.) & MRSA(no.) & MSSA(no.) & scCmec(no.) & MLST(no.) & spa(no.) & MRSA(no.) & MSSA(no.) & scCmec(no.) \\
\hline & & t2207(3) & 3 & & NT(3) & & $\mathrm{t} 2207(2)$ & 2 & & NT(2) \\
\hline & ST610(1) & t2207(1) & 1 & & $\|(1)$ & & $\mathrm{t} 114(1)$ & & 1 & \\
\hline & & & & & & ST2583(1) & $\mathrm{t} 1381(1)$ & 1 & & $\operatorname{IVa}(1)$ \\
\hline \multirow[t]{5}{*}{ CC8(9) } & ST239(3) & t030(2) & 2 & & $\|(2)$ & ST239(3) & t030(2) & 2 & & $\|(2)$ \\
\hline & & t037(1) & 1 & & $\|(1)$ & & t037(1) & 1 & & $\|(1)$ \\
\hline & & & & & & ST630(2) & $\mathrm{t} 377(1)$ & & 1 & \\
\hline & & & & & & & $\mathrm{t} 4549(1)$ & & 1 & \\
\hline & & & & & & ST5492(1) & t1987(1) & & 1 & \\
\hline \multirow[t]{2}{*}{ CC2580(6) } & ST2580(5) & t3351(4) & 4 & & $\operatorname{IVa}(1), \operatorname{IVc}(3)$ & ST2580(1) & t3351(1) & 1 & & $\operatorname{IVc}(1)$ \\
\hline & & t4875(1) & 1 & & $\operatorname{IVc}(1)$ & & & & & \\
\hline \multirow[t]{2}{*}{$\operatorname{CC72(6)}$} & ST72(2) & $\mathrm{t} 148(2)$ & & 2 & & ST72(4) & $\mathrm{t} 148(3)$ & & 3 & \\
\hline & & & & & & & t3092(1) & & 1 & \\
\hline \multirow[t]{3}{*}{$\mathrm{CC} 121(5)$} & ST121(4) & $\mathrm{t} 269(1)$ & & 1 & & ST120(1) & t2613(1) & 1 & & NT(1) \\
\hline & & $\mathrm{t} 162(2)$ & & 2 & & & & & & \\
\hline & & t159(1) & & 1 & & & & & & \\
\hline \multirow[t]{2}{*}{ CC15(4) } & ST15(1) & t1492(1) & & 1 & & ST15(1) & t085(1) & & 1 & \\
\hline & ST4438(2) & t084(2) & & 2 & & & & & & \\
\hline \multirow[t]{2}{*}{ CC97(3) } & ST464(1) & t3992(1) & & 1 & & ST97(1) & $\mathrm{t} 267(1)$ & & 1 & \\
\hline & & & & & & ST464(1) & t3904(1) & & 1 & \\
\hline CC2196(3) & ST4435(1) & t037(1) & 1 & & $\operatorname{IVa}(1)$ & ST2196(2) & NT(2) & & 2 & \\
\hline $\operatorname{CC9}(2)$ & ST9(1) & t899(1) & & 1 & & ST9(1) & t899(1) & 1 & & $\mathrm{I}(1)$ \\
\hline CC509(2) & & & & & & ST509(2) & $\mathrm{t} 375(2)$ & 1 & 1 & $\operatorname{IVa}(1)$ \\
\hline CC1281(2) & & & & & & ST1281(2) & $\mathrm{t} 164(2)$ & & 2 & \\
\hline CC25(2) & ST5493(1) & t12584(1) & & 1 & & ST25(1) & $\mathrm{t} 280(1)$ & & 1 & \\
\hline \multirow[t]{2}{*}{ Singletons(2) } & ST6(1) & $\mathrm{t} 304(1)$ & 1 & & $\operatorname{IVa}(1)$ & & & & & \\
\hline & ST944(1) & t616(1) & & 1 & & & & & & \\
\hline
\end{tabular}

NT Non-typeable

and all ST45-MRSA isolates belonged to the SCCmec IVa type (Tables 2 and 3). The ST398 $\left(x^{2}=17.685, p<\right.$ $0.01)$ and ST188 isolates $(p<0.01)$ had higher resistance rates to TET than the ST45 isolates. In addition, no significant difference was seen in the resistance rate to any antibiotics between ST398, ST188 and ST45 isolates.

Of the 11 tested virulence genes, $p v l$ and $f n b B$ were more frequent in ST398 isolates than in ST45 $\left(\mathrm{X}^{2}=\right.$ 22.010 and $\chi^{2}=30.457$, respectively, $\left.p<0.01\right)$ and ST188 isolates $\left(X^{2}=12.790\right.$ and $X^{2}=38.027$, respectively, $p<$ $0.01)$. The prevalence of sec in ST45 isolates was higher than that in ST398 $\left(\chi^{2}=43.487, p<0.01\right)$ and ST188 isolates $\left(X^{2}=32.500, p<0.01\right)$, whereas the prevalence of eta in ST45 isolates was higher than in ST188 isolates $\left(X^{2}=14.339, p<0.01\right)$. On the contrary, the positive rate of $h l b$ in ST45 isolates was lower than in ST398 $\left(\chi^{2}=\right.$ $7.118, p<0.01)$ and ST188 isolates $\left(x^{2}=7.248, p<0.01\right)$. No significant difference was found in the positive rate of any other virulence genes between any two of the three STs (Table 4).

\section{Discussion}

A total of 227 S. aureus isolates were collected in 20132014 and 2018-2019 from three hospitals in Hainan province for investigation of their antimicrobial resistance, virulence gene profiles, and molecular characteristics. The results showed that all isolates were susceptible to VAN and LZD, in agreement with most previous studies in mainland China [29-31]. In addition, when comparing the $S$. aureus isolates collected in 2013-2014 and 2018-2019, no significant difference was found in the resistance rates to the remaining antibiotics except that to SXT. Therefore, both sets of isolates were combined for analysis, and the average resistance rates to PEN, ERY, CLI, TET, FOX, OXA, GEN, LEV, and RIF were found to be $92.5,48.9,41.4,37.4,33.5,33.0,11.9$, 


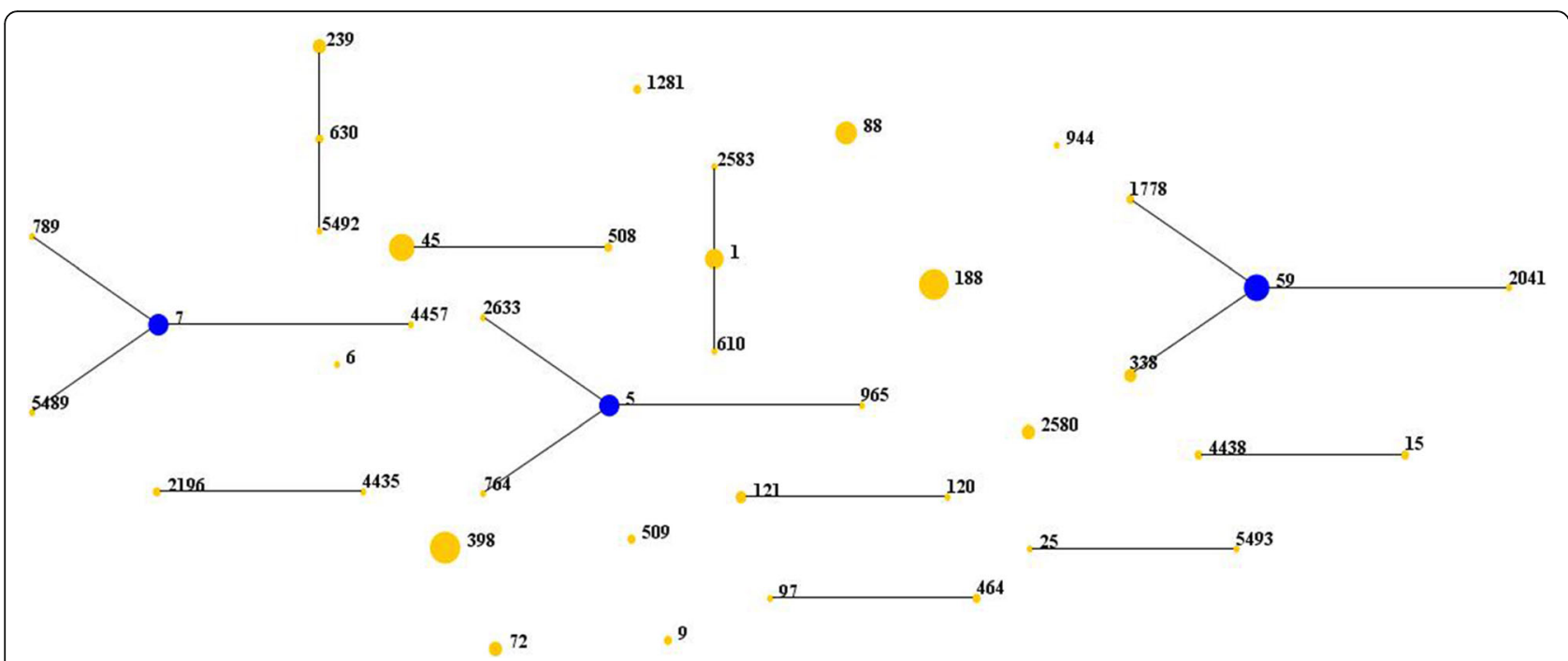

Fig. 2 Distribution of STs in the clonal complexes. The diagram generated by eBURST based on the MLST data of this study, representing the relationships of 227 S. aureus isolates identified by MLST typing. Each number implies an MLST ST, STs that are linked by a line belong to the same cluster and the dot area indicates the prevalence of the ST in the MLST data of this study

9.7, and $8.8 \%$, respectively. For comparison, in mainland China in the first half of 2018, the corresponding average rates were reported to be $92.7,64.5,38.4 \%$, unreported, $34.4,34.4,18.7,22.4$, and $5.2 \%$ (www.chinets.com). While in Turkey in 2017, the average rates to OXA, RIF, VAN and LZD were 23.0, 14.0, 0.0, and 0.0\%, respectively. In the United States in 2017, the average rates to OXA, ERY, RIF, VAN, and LZD were 45.0, 41.0, 1.0, 0.0, and $0.0 \%$, respectively, whereas in Russia in 2017, they were 16.0, 2.0, 0.0, and 0.0\%, and in Australia they were $19.0,1.0,1.0$, and $0.0 \%$, respectively (resistancemap. cddep.org/AntibioticResistance.php). The S. aureus isolates from Hainan had resistance rates against some antibiotics similar to those from mainland China and other countries, but differences were found in the resistance rates to ERY and LEV. In addition, the resistance rate to SXT in the S. aureus isolates collected in 2018-2019 (5.9\%) was significantly lower than for those collected in 2013-2014 (64.8\%), whereas the resistance rate to SXT has remained stable in recent years in mainland China. $10.1 \%$ in 2014 and $14.3 \%$ in the first half of 2018 (http:// www.chinets.com). The steep decline in resistance to SXT may be due to the reduced use of this antibiotic in recent years in Hainan.

ERY and TET resistance depend on the presence of resistance genes erm and tet, respectively. The predominant resistance gene in the ERY-resistant isolates was erm $C$, which differed from previous studies in which most of the ERY-resistant strains harboured $\operatorname{ermA}[27$, 32]. In this study, ermB was present in $38.7 \%$ of ERY-

Table 4 The frequency of virulence genes among main types of S. aureus isolates and the comparison of two time periods

\begin{tabular}{|c|c|c|c|c|c|c|c|}
\hline $\begin{array}{l}\text { Virulence } \\
\text { genes }\end{array}$ & $\begin{array}{l}\text { S. aureus }(n= \\
227) n(\%)\end{array}$ & $\begin{array}{l}\text { ST398 }(n= \\
32) n(\%)\end{array}$ & $\begin{array}{l}\text { ST188 }(n= \\
\text { 30)n(\%) }\end{array}$ & $\begin{array}{l}\text { ST45 }(n= \\
\text { 23)n(\%) }\end{array}$ & $\begin{array}{l}\text { 2013-2014 }(n= \\
91) \mathrm{n}(\%)\end{array}$ & $\begin{array}{l}2018-2019(n= \\
136) n(\%)\end{array}$ & $\begin{array}{l}P \\
\text { value }^{\text {a }}\end{array}$ \\
\hline$p v l$ & $108(47.6)$ & $26(81.3)$ & $11(36.7)$ & $4(17.4)$ & $25(27.5)$ & $83(61.0)$ & $<0.01$ \\
\hline$f n b A$ & 87 (35.7) & $7(21.9)$ & 7 (23.3) & $10(43.5)$ & $33(36.3)$ & 54 (39.7) & 0.601 \\
\hline$f \cap b B$ & $113(49.8)$ & 31 (96.9) & $6(20.0)$ & $6(26.1)$ & 19 (20.9) & $94(69.1)$ & $<0.01$ \\
\hline hla & $224(98.7)$ & $32(100.0)$ & $29(96.7)$ & $23(100.0)$ & $91(100.0)$ & $133(97.8)$ & 0.405 \\
\hline$h / b$ & $161(70.9)$ & $20(62.5)$ & 19 (63.3) & $6(26.1)$ & $44(48.4)$ & $117(86.0)$ & $<0.01$ \\
\hline sea & 35 (15.4) & $5(15.6)$ & $2(6.7)$ & $1(4.3)$ & $13(14.3)$ & $22(16.2)$ & 0.699 \\
\hline seb & $108(47.6)$ & $11(34.4)$ & $18(60.0)$ & $8(34.8)$ & 35 (38.5) & $73(53.7)$ & 0.024 \\
\hline $\mathrm{sec}$ & $63(27.8)$ & $2(6.3)$ & $5(16.7)$ & $22(95.7)$ & $28(30.8)$ & 35 (25.7) & 0.406 \\
\hline eta & $130(57.3)$ & $24(75.0)$ & $14(46.7)$ & $22(95.7)$ & $21(23.1)$ & $109(80.1)$ & $<0.01$ \\
\hline etb & 43 (18.9) & $10(31.3)$ & $6(20.0)$ & $3(13.0)$ & $0(0.0)$ & $43(31.6)$ & $<0.01$ \\
\hline CIfA & $227(100.0)$ & $32(100.0)$ & $30(100.0)$ & $23(100.0)$ & $91(100.0)$ & $136(100.0)$ & - \\
\hline
\end{tabular}

${ }^{\mathrm{a}}$ The frequency of virulence genes of $S$. aureus isolates in 2013-2014 were compared with those in 2018-2019 
resistant isolates, whereas in most previous studies, ermB was rare or not detected at all $[27,32]$. Therefore it is concluded that $S$. aureus isolates in Hainan have characteristic resistance genes for erythromycin resistance. Most of the TET-resistanct isolates harbored tet $M$ and tet $K$, which indicates that those variants were responsible for resistance to TET, consistent with previous studies [28, 32, 33]. Our study shows that the frequency of tet $M$ was higher in TET-resistant MRSAs than in TET-resistant MSSAs, consistent with the previous finding that the resistance mechanism mediated by tet $M$ is predominant among TET-resistant MRSAs [34].

MLST typing, spa typing, and SCCmec typing were performed to analyze the molecular characteristics of the S. aureus isolates. ST398, ST188, and ST45 were the predominant STs among the $S$. aureus isolates in this study, among which ST398 and ST45 were the predominant clones in the MSSA and MRSA isolates, respectively. In addition, the most common SCCmec type was IVa, and ST45-SCCmec IVa was the most prevalent combination of ST and SCCmec typing in the MRSA isolates. ST188 and ST239 were previously reported as the predominant STs in MSSA and MRSA isolates, respectively $[11,19,20,35,36]$. Two of these studies were multicenter studies that showed that ST239-SCCmec III was the predominant MRSA genotype, but no ST45 clones were observed $[11,20]$. A recent study in Shanghai showed that ST239-t030 and ST239-t037 were being driven out by the continual growth of the ST5-t2460 clone [14]. Therefore, it can be concluded that the molecular characteristics of $S$. aureus isolates in Hainan differ significantly from those in mainland China. It is reasonable to speculate that the divergent molecular characteristics of $S$. aureus isolates in Hainan are associated with the special geographical location of Hainan.

ST398 MSSA was found to be the most prevalent in Hainan province, and the patients with the ST398 MSSA isolates had no history of contact with livestock, confirming that the ST398 MSSA isolates we collected are of human origin. In addition, in the short span of 5 years, the prevalence of ST398 MSSA increased from 5.5 to $18.4 \%$ in Hainan. Similar to the epidemic situation in Hainan province, ST398 MSSA have been increasingly reported as a cause of invasive infections in patients without livestock contact [4]. In cohorts of patients in France, the number of ST398 MSSA cases was shown to increase from zero in 1999 to $4.6 \%$ in 2010, including $13.8 \%$ of cases with $S$. aureus bloodstream infections [4, 37]. Another retrospective study in France found that only $1.9 \%$ of bone and joint infection (BJI) MSSA strains were screened to be ST398 in 2008, whereas in 20102012, 14.0\% of BJI MSSA strains belonged to ST398 [38]. Therefore, ST398 MSSA has emerged as an invasive pathogen causes bloodstream infections, BJIs, and potentially other conditions. Evidence suggests that ST398 MRSA and ST398 MSSA belong to distinct lineages [39]. It is well known that the ST398 MRSA lineage, associated with livestock, has become a worldwide threat within the past decade [4]. However, ST398 MSSA is a frequent source of $S$. aureus infections between individuals in households. This contrasts with the limited transmissibility of livestock-associated ST398 MRSA strains between humans [40]. ST398 MSSA has enhanced adhesion to human skin keratinocytes and keratin and it is more closely linked with human infections than ST398 MRSA. In addition, it was reported that the 30-day allcause mortality was higher for patients with ST398 MSSA bloodstream infection than for a control group with non-ST398 MSSA infection [4]. Because ST398 MSSA has become the most prevalent ST in S. aureus isolates from Hainan and may be linked to higher mortality, it is necessary to monitor the changes in the molecular characteristics of $S$. aureus to prevent the wider dissemination of that strain.

The virulence factors of $S$. aureus play an important role during pathogenesis $[41,42]$. Similar to the majority of studies in mainland China [8,43], almost all strains in our study were positive for $c l f A$ and $h l a$, confirming that these were the most common virulence factors in S. aureus, and no regional difference was seen in their distribution. Notably, the frequencies of eta and $p v l$ were 57.3 and $47.6 \%$, much higher than those in mainland China $[10,16,19]$. ST45, a common type of S. aureus isolate in Hainan, was found to have an eta prevalence of $95.7 \%$ in our results. Meanwhile, ST398, a clone with a low prevalence of $p v l$ in previous studies [37, 40], had a frequency of $81.3 \%$ in this study. Together, these findings indicate that $S$. aureus isolates in Hainan have somewhat higher positive rates of eta and $p v l$. Previous studies reported some virulence genes are linked to specific molecular types [43, 44]. For example, ST8 (USA300) was linked to the acquisition of the enterotoxin Q and K genes. ST36 (USA200) was associated with the acquisition of the enterotoxin A gene and the toxic shock syndrome toxin 1 gene [44]. Therefore, it is rational to speculate that the higher rates of eta and $p v l$ could be associated with the different distribution of STs. This implies that the molecular characteristics of $S$. aureus isolates affect their virulence gene profiles, leading us to conclude that $S$. aureus isolates collected in Hainan have distinct virulence gene profiles compared with those collected in mainland China. In addition, compared with the 20132014 isolates, the S. aureus isolates collected in 20182019 carried more virulence genes, but their rate of MDR was lower. The opposite trend between antibiotic resistance and virulence may be related to balance the energetic requirements for expressing resistance and producing toxins, which suggests that the antibiotic 
resistance and virulence of pathogens are in competition during evolution $[45,46]$. This study has some limitations. First, the small sample size limited the broad representativeness of the study. Second, we had no information about the relationship between clinical data (e.g. mortality, severity) and molecular characteristics of the isolates, which will be the focus in further research. These fields.

\section{Conclusions}

S. aureus isolates in Hainan have unique molecular characteristics and virulence gene profiles. ST398-MSSA was the most common type of MSSA isolate and ST45SCCmec IVa was the predominant type of MRSA isolate, neither of which had been reported in China before. Differences were also found between the antibiotic resistance and virulence gene profiles of the ST398 and ST45 isolates. ST398-MSSA showed a clear growth trend from 2013 to 2014 to 2018-2019, which deserves attention from public health services.

\section{Abbreviations}

CC: Clonal complex; MDR: Multidrug resistance; MLST: Multilocus sequence typing; MRSA: Methicillin-resistant Staphylococcus aureus; MSSA: Methicillinsusceptible Staphylococcus aureus; OS-MRSA: Oxacillin susceptible-MRSA; PVL: Panton-Valentine leukocidin; S. aureus: Staphylococcus aureus;

SCCmec: Staphylococcus chromosomal cassette mec

\section{Acknowledgments}

We are grateful to Hainan General Hospital, Haikou People's Hospital and The First Affiliated Hospital of Hainan Medical college for providing clinical isolates and data.

\section{Authors' contributions}

$Y L$ designed the studies and obtained funding; $X L$ performed the experiments; $X L$ and $C L$ performed the statistical analysis; $X L$ wrote the manuscript; YL contributed to manuscript revision; $\mathrm{KX}$ and TH contributed the materials. All authors read and approved the submitted version.

\section{Funding}

This work was supported by the National Natural Science Foundation of China (Grant No. 81371779) and the Natural Science Foundation of Hubei Province (Grant No. 2016CFB672). The funding bodies had no role in the design of the study and collection, analysis, and interpretation of data and in writing the manuscript.

\section{Availability of data and materials}

The datasets used and/or analysed during the current study are available from the corresponding author on reasonable request.

\section{Ethics approval and consent to participate}

This study was approved by the Ethics Committee of Hainan General Hospital. This was a retrospective study without any collection of clinical and personal information from patients, so informed consent was not required.

\section{Consent for publication}

Not applicable.

\section{Competing interests}

The authors declare that they have no competing interests.

\section{Author details}

'Department of Laboratory Medicine, Zhongnan Hospital, Wuhan University, 169 Donghu Road, Wuhan 430071, People's Republic of China. ${ }^{2}$ Department of Laboratory Medicine, Hainan General Hospital, Haikou, China. ${ }^{3}$ Center of
Laboratory Medicine, National Center for Cardiovascular Diseases \& Fuwai Hospital, Peking Union Medical College \& Chinese Academy of Medical Sciences, Beijing, China.

Received: 27 June 2019 Accepted: 9 October 2019

Published online: 22 October 2019

\section{References}

1. Chiu-Hsia S, Chang S-C, Yan J-J, Tseng S-H, Chien L-J, Fang C-T. Excess mortality and long-term disability from healthcare-associated staphylococcusaureus infections: a population-based matched cohort study. PLOS One. 2013;8(8):e71055.

2. Chen $\mathrm{H}$, Liu Y, Jiang $X$, Chen M, Wang $H$. Rapid change of methicillinresistant Staphylococcus aureus clones in a Chinese tertiary care hospital over a 15-year period. Antimicrob Agents Chemother. 2010;54(5):1842-7.

3. Rao Q, Rao X, Hu X, Shang W. Staphylococcus aureus ST121: a globally disseminated hypervirulent clone. J Med Microbiol. 2015;64(12):1462-73.

4. Bouiller K, Gbaguidi-Haore H, Hocquet D, Cholley P, Bertrand X, Chirouze C. Clonal complex 398 methicillin-susceptible Staphylococcus aureus bloodstream infections are associated with high mortality. Clin Microbiol Infect. 2016;22(5):451-5.

5. Cheng H, Yuan W, Zeng F, Hu Q, Shang W, Tang D, Xue W, Fu J, Liu J, Liu $\mathrm{N}$, et al. Molecular and phenotypic evidence for the spread of three major methicillin-resistant Staphylococcus aureus clones associated with two characteristic antimicrobial resistance profiles in China. J Antimicrob Chemother. 2013:68(11):2453-7.

6. Htun HL, Kyaw WM, de Sessions PF, Low L, Hibberd ML, Chow A, Leo YS. Methicillin-resistant Staphylococcus aureus colonisation: epidemiological and molecular characteristics in an acute-care tertiary hospital in Singapore. Epidemiol Infect. 2018;146(14):1785-92.

7. Kitti T, Seng R, Saiprom N, Thummeepak R, Chantratita N, Boonlao C, Sitthisak S. Molecular characteristics of methicillin-resistant staphylococci clinical isolates from a tertiary Hospital in Northern Thailand. Can J Infect Dis Med Microbiol. 2018;2018:8457012.

8. Peng H, Liu D, Ma Y, Gao W. Comparison of community- and healthcareassociated methicillin-resistant Staphylococcus aureus isolates at a Chinese tertiary hospital, 2012-2017. Sci Rep. 2018;8(1):17916.

9. O'Hara FP, Amrine-Madsen H, Mera RM, Brown ML, Close NM, Suaya JA, Acosta CJ. Molecular characterization ofStaphylococcus aureus in the United States 2004-2008 reveals the rapid expansion of USA300 among inpatients and outpatients. Microb Drug Resist. 2012;18(6):555-61.

10. Yu F, Li T, Huang X, Xie J, Xu Y, Tu J, Qin Z, Parsons C, Wang J, Hu L, et al. Virulence gene profiling and molecular characterization of hospital-acquired Staphylococcus aureus isolates associated with bloodstream infection. Diagn Microbiol Infect Dis. 2012;74(4):363-8.

11. Liu Y, Wang H, Du N, Shen E, Chen H, Niu J, Ye H, Chen M. Molecular evidence for spread of two major methicillin-resistant Staphylococcus aureus clones with a unique geographic distribution in Chinese hospitals. Antimicrob Agents Chemother. 2009;53(2):512-8.

12. Tan S, Wan C, Wang H, Zhou W, Shu M. Relationship between nasal carrier isolates and clinical isolates in children with Staphylococcus aureus infections. Microb Pathog. 2019;127:233-8.

13. Li S, Sun S, Yang C, Chen H, Yin Y, Li H, Zhao C, Wang H. The changing pattern of population structure of Staphylococcus aureus from bacteremia in China from 2013 to 2016: ST239-030-MRSA replaced by ST59-4437. Front Microbiol. 2018;9:332.

14. Dai Y, Liu J, Guo W, Meng H, Huang Q, He L, Gao Q, Lv H, Liu Y, Wang Y, et al. Decreasing methicillin-resistant Staphylococcus aureus (MRSA) infections is attributable to the disappearance of predominant MRSA ST239 clones, Shanghai, 2008-2017. Emerg Microbes Infect. 2019;8(1):471-8.

15. Ding YL, Fu J, Chen J, Mo SF, Xu S, Lin N, Qin P, McGrath E. Molecular characterization and antimicrobial susceptibility of Staphylococcus aureus isolated from children with acute otitis media in Liuzhou, China. BMC Pediatr. 2018;18(1):338

16. Liu Q, Han L, Li B, Sun J, Ni Y. Virulence characteristic and MLST-agr genetic background of high-level Mupirocin-resistant, MRSA isolates from Shanghai and Wenzhou, China. PLoS One. 2012;7(5):e37005.

17. Wu D, Wang Z, Wang H, Sun L, Chen Y, Ji S, Shi K, Yu Y. Predominance of ST5-II-t311 clone among healthcare-associated methicillin-resistant Staphylococcus aureus isolates recovered from Zhejiang, China. Int I Infect Dis. 2018;71:107-12. 
18. Xie X, Bao Y, Ouyang N, Dai X, Pan K, Chen B, Deng Y, Wu X, Xu F, Li H, et al. Molecular epidemiology and characteristic of virulence gene of community-acquired and hospital-acquired methicillin-resistant Staphylococcus aureus isolates in Sun Yat-sen memorial hospital, Guangzhou, Southern China. BMC Infect Dis. 2016;16:339.

19. Liu C, Chen ZJ, Sun Z, Feng X, Zou M, Cao W, Wang S, Zeng J, Wang Y, Sun M. Molecular characteristics and virulence factors in methicillin-susceptible, resistant, and heterogeneous vancomycin-intermediate Staphylococcus aureus from Central-Southern China. J Microbiol Immunol Infect. 2015;48(5): 490-6.

20. Zhang H, Xiao M, Kong F, O'Sullivan MVN, Mao L-L, Zhao H-R, Zhao Y, Wang $\mathrm{H}, \mathrm{Xu}$ Y-C. A multicentre study of meticillin-resistant Staphylococcus aureus in acute bacterial skin and skin-structure infections in China: susceptibility to ceftaroline and molecular epidemiology. Int J Antimicrob Agents. 2015; 45(4):347-50.

21. CLSI, editor. Performance standards for antimicrobial suscepetibility testing, 29th ed. CLSI supplement M100. Wayne: Clinical and Laboratory Standards Institute; 2019.

22. Zhang K, McClure J-A, Elsayed S, Louie T, Conly JM. Novel multiplex PCR assay for characterization and concomitant subtyping of staphylococcal cassette chromosome mec types I to $\mathrm{V}$ in methicillin-resistant Staphylococcus aureus. J Clin Microbiol. 2005;43(10):5026-33.

23. Li X, Fang F, Zhao J, Lou N, Li C, Huang T, Li Y. Molecular characteristics and virulence gene profiles of Staphylococcus aureus causing bloodstream infection. Braz J Infect Dis. 2018;22(6):487-94.

24. Strommenger B, Kettlitz C, Weniger T, Harmsen D, Friedrich AW, Witte W. Assignment of Staphylococcus isolates to groups by spa typing, Smal macrorestriction analysis, and multilocus sequence typing. J Clin Microbiol. 2006;44(7):2533-40.

25. Enright MC, Day NP, Davies CE, Peacock SJ, Spratt BG. Multilocus sequence typing for characterization of methicillin-resistant and methicillin-susceptible clones of Staphylococcus aureus. J Clin Microbiol. 2000;38(3):1008-15.

26. Boye K, Bartels MD, Andersen IS, Møller JA, Westh H. A new multiplex PCR for easy screening of methicillin-resistant Staphylococcus aureus SCCmec types I-V. Clin Microbiol Infect. 2007;13:725-7.

27. Lina G, Quaglia A, Reverdy ME, Leclercq R, Vandenesch F, Etienne J. Distribution of genes encoding resistance to macrolides, lincosamides, and streptogramins among staphylococci. Antimicrob Agents Chemother. 1999; 43(5):1062-6.

28. Emaneini M, Bigverdi R, Kalantar D, Soroush S, Jabalameli F, Noorazar Khoshgnab B, Asadollahi P, Taherikalani M. Distribution of genes encoding tetracycline resistance and aminoglycoside modifying enzymes in staphylococcus aureus strains isolated from a burn center. Ann Burns Fire Disasters. 2013;16(2):76-80.

29. Li T, Yu X, Xie J, Xu Y, Shang Y, Liu Y, Huang X, Qin Z, Parsons C, Hu L, et al. Carriage of virulence factors and molecular characteristics of Staphylococcus aureus isolates associated with bloodstream, and skin and soft tissue infections in children. Epidemiol Infect. 2013;141(10):2158-62.

30. Rong D, Wu Q, Xu M, Zhang J, Yu S. Prevalence, virulence genes, antimicrobial susceptibility, and genetic diversity of Staphylococcus aureus from retail aquatic products in China. Front Microbiol. 2017:8:714.

31. Yu Y, Yao Y, Weng Q, Li J, Huang J, Liao Y, Zhu F, Zhao Q, Shen X, Niu J. Dissemination and molecular characterization of Staphylococcus aureus at a tertiary referral hospital in Xiamen city, China. BioMed Res Int. 2017;2017: 1367179.

32. Lim KT, Hanifah YA, Yusof M, Thong KL. ermA, ermC, tetM and tetK are essential for erythromycin and tetracycline resistance among methicillinresistant Staphylococcus aureus strains isolated from a tertiary hospital in Malaysia. Indian J Med Microbiol. 2012;30(2):203-7.

33. Lozano C, Porres-Osante N, Crettaz J, Rojo-Bezares B, Benito D, Olarte I, Zarazaga M, Sáenz $Y$, Torres $C$. Changes in genetic lineages, resistance, and virulence in clinical methicillin-resistant Staphylococcus aureus in a Spanish hospital. J Infect Chemother. 2013;19(2):233-42.

34. Schmitz FJ, Krey A, Sadurski R, Verhoef J, Milatovic D, Fluit AC, European SENTRY Participants. Resistance to tetracycline and distribution of tetracycline resistance genes in European Staphylococcus aureus isolates. J Antimicrob Chemother. 2001;47(2):239-40.

35. He W, Chen H, Zhao C, Zhang F, Li H, Wang Q, Wang X, Wang H. Population structure and characterisation of Staphylococcus aureus from bacteraemia at multiple hospitals in China: association between antimicrobial resistance, toxin genes and genotypes. Int J Antimicrob Agents. 2013;42(3):211-9.

36. Wang Y, Liu Q, Liu Q, Gao Q, Lu H, Meng H, Xie Y, Huang Q, Ma X, Wang H, et al. Phylogenetic analysis and virulence determinant of the host-adapted Staphylococcus aureus lineage ST188 in China. Emerg Microbes Infect. 2018; 7(1):45

37. Jewell $P$, Dixon $L$, Singanayagam A, Ghani R, Wong E, Coleman M, Pichon B, Kearns A, Russell G, Hatcher J. Severe disseminated infection with emerging lineage of methicillin-sensitive Staphylococcus aureus. Emerg Infect Dis. 2019;25(1):187-9.

38. Valour F, Tasse J, Trouillet-Assant S, Rasigade J-P, Lamy B, Chanard E, Verhoeven P, Decousser J-W, Marchandin H, Bes M, et al. Methicillinsusceptible Staphylococcus aureus clonal complex 398: high prevalence and geographical heterogeneity in bone and joint infection and nasal carriage. Clin Microbiol Infect. 2014;20:0772-5.

39. Smith TC, Wardyn SE. Human infections with Staphylococcus aureus CC398. Curr Environ Health Rep. 2015;2(1):41-51.

40. Uhlemann AC, McAdam PR, Sullivan SB, Knox JR, Khiabanian H, Rabadan R, Davies PR, Fitzgerald JR, Lowy FD. Evolutionary dynamics of pandemic methicillin-sensitive Staphylococcus aureus ST398 and its international spread via routes of human migration. MBio. 2017;8:e01375-16.

41. Diep BA, Otto M. The role of virulence determinants in communityassociated MRSA pathogenesis. Trends Microbiol. 2008;16(8):361-9.

42. Yu F, Yang L, Pan J, Chen C, Du J, Li Q, Huang J, Zhang X, Wang L. Prevalence of virulence genes among invasive and colonising Staphylococcus aureus isolates. J Hosp Infect. 2011;77(1):89-91.

43. Wang X, Li X, Liu W, Huang W, Fu Q, Li M. Molecular characteristic and virulence gene profiles of community-associated methicillin-resistant Staphylococcus aureus isolates from pediatric patients in Shanghai, China. Front Microbiol. 2016;7:1818.

44. Diep BA, Carleton HA, Chang RF, Sensabaugh GF, Perdreau-Remington F. Roles of 34 virulence genes in the evolution of hospital- and communityassociated strains of methicillin-resistant Staphylococcus aureus. J Infect Dis. 2006;193(11):1495-503.

45. Rudkin JK, Edwards AM, Bowden MG, Brown EL, Pozzi C, Waters EM, Chan WC, Williams P, O'Gara JP, Massey RC. Methicillin resistance reduces the virulence of healthcare-associated methicillin-resistant Staphylococcus aureus by interfering with the agr quorum sensing system. J Infect Dis. 2012;205(5):798-806

46. He L, Zheng H-X, Wang Y, Le KY, Liu Q, Shang J, Dai Y, Meng H, Wang X, Li $T$, et al. Detection and analysis of methicillin-resistant human-adapted sequence type 398 allows insight into community-associated methicillinresistant Staphylococcus aureus evolution. Genome Med. 2018;10(1):5.

\section{Publisher's Note}

Springer Nature remains neutral with regard to jurisdictional claims in published maps and institutional affiliations.

Ready to submit your research? Choose BMC and benefit from:

- fast, convenient online submission

- thorough peer review by experienced researchers in your field

- rapid publication on acceptance

- support for research data, including large and complex data types

- gold Open Access which fosters wider collaboration and increased citations

- maximum visibility for your research: over $100 \mathrm{M}$ website views per year

At BMC, research is always in progress.

Learn more biomedcentral.com/submissions 